\title{
Gastric digestion of milk protein ingredients: Study using an in vitro dynamic model
}

\author{
Xin Wang, ${ }^{*} \dagger$ Aiqian Ye, ${ }^{*}{ }^{1}$ Quanquan Lin, $\dagger$ Jianzhong Han, ${ }^{*}$ and Harjinder Singh $\dagger$ \\ ${ }^{*}$ College of Food and Biotechnology, Zhejiang Gongshang University, Hangzhou 310018, China \\ †Riddet Institute and Massey Institute of Food Science and Technology, Massey University, Palmerston North 4442, New Zealand
}

\section{ABSTRACT}

The coagulation behavior and the kinetics of protein hydrolysis of skim milk powder, milk protein concentrate (MPC), calcium-depleted MPC, sodium caseinate, whey protein isolate (WPI), and heated $\left(90^{\circ} \mathrm{C}\right.$, $20 \mathrm{~min}$ ) WPI under gastric conditions were examined using an advanced dynamic digestion model (i.e., a human gastric simulator). During gastric digestion, these protein ingredients exhibited various $\mathrm{pH}$ profiles as a function of the digestion time. Skim milk powder and MPC, which contained casein micelles, formed cohesive, ball-like curds with a dense structure after $10 \mathrm{~min}$ of digestion; these curds did not disintegrate over 220 min of digestion. Partly calcium-depleted MPC and sodium caseinate, which lacked an intact casein micellar structure, formed curds at approximately $40 \mathrm{~min}$, and a loose, fragmented curd structure was observed after 220 min of digestion. In contrast, no curds were formed in either WPI or heated WPI after 220 min of digestion. In addition, the hydrolysis rates and the compositions of the digesta released from the human gastric simulator were different for the various protein ingredients, as detected by sodium dodecyl sulfate-PAGE. Skim milk powder and MPC exhibited slower hydrolysis rates than calcium-depleted MPC and sodium caseinate. The most rapid hydrolysis occurred in the WPI (with and without heating). This was attributed to the formation of different structured curds under gastric conditions. The results offer novel insights about the coagulation kinetics of proteins from different milk protein ingredients, highlighting the critical role of the food matrix in affecting the course of protein digestion.

Key words: milk protein, curd structure, coagulation, gastric digestion, hydrolysis

Received December 13, 2017.

Accepted April 5, 2018.

${ }^{1}$ Corresponding author: A.M.Ye@massey.ac.nz

\section{INTRODUCTION}

Milk protein is an important source of nutrients for humans through the different stages of life. A range of milk protein ingredients are used to improve the functional properties and nutritional value of food products. Skim milk powder (SMP), milk protein concentrate (MPC), sodium caseinate, and whey protein isolate (WPI) are the most extensively used protein ingredients in foods and nutritional products.

Skim milk powder is the most widely applied functional dairy ingredient (Singh and Creamer, 1991). Its manufacture involves heat treatment, normally known as preheating, evaporation, and spray drying. The most important effect of the preheating is the induction of the denaturation of the whey proteins to give partially denatured whey proteins, which can simply self-aggregate or can associate with the casein micelles via micellar k-CN or both (Singh, 2007).

Milk protein concentrate was the first membraneproduced, casein-based product on the market (Carr and Golding, 2016). The caseins and whey proteins are in the same proportions as in milk. The casein is in a micellar form and the whey protein is in its native state because the manufacturing process does not involve preheating. However, a fraction of the colloidal calcium phosphate in MPC may be dissolved during the manufacturing process, leading to loose casein micelle structures and resulting in a smaller fragmented micellar structure (Singh, 2007).

To improve the functional properties of MPC, the casein micelles in some new products have been dissociated to a certain extent by removing the calcium (Ye, 2011). This type of product is referred to as "calciumdepleted MPC" in the present study. The micellar structure of MPC can be converted from the native structure to a structure that is closer to that of sodium caseinate, depending on the level of calcium depletion (Carr and Golding, 2016). However, a significant difference between caseinate and MPC is that MPC contain phosphate, whereas caseinate has reduced phosphate levels because of acidic precipitation and subsequent washing. Micellar phosphate increases the buffer- 
ing capacity because of the formation of dihydrogen phosphate (Ferreira et al., 2003) on the acid-mediated solubilization of colloidal calcium phosphate (Carr and Golding, 2016).

Sodium caseinate, the water-soluble form of casein that is most commonly used in foods, is usually prepared by solubilizing acid casein with $\mathrm{NaOH}$ (Mulvihill and Ennis, 2003). The products produced in this manner contain individual casein molecules because the native micellar structure is disrupted during the manufacturing process. The excellent heat stability of caseinates is one of their most important functional benefits; it limits alterations to their properties as a consequence of thermal processing (Carr and Golding, 2016).

Whey is co-product of casein production and cheese making (Carr and Golding, 2016). Whey protein ingredients that contain $\geq 90 \%$ protein are known as WPI. To produce WPI, whey is skimmed by centrifugation or microfiltration and then demineralized by ion exchange, electrodialysis, or nanofiltration. The proteins are concentrated by membrane filtration or ion exchange chromatographic methods (Bansal and Bhandari, 2016). Because the whey protein in WPI is in its native state, its functional properties are largely retained.

Whey protein and casein are usually used as model proteins in studies to investigate the digestion and absorption rate of protein (He and Giuseppin, 2014). Boirie et al. (1997) proposed the concepts of slow casein and fast whey protein according to the different digestion rates of these proteins. Because whey protein is reported to induce a dramatic but short increase in plasma AA after ingestion, it is classified as a fast protein. It has a fast gastric emptying rate, because it stays soluble in the stomach and passes into the small intestine rapidly without being hydrolyzed by pepsin (Boirie et al., 1997; He and Giuseppin, 2014). In contrast, casein is classified as a slow protein for digestion. Casein forms clots in the stomach, which greatly reduces the gastric emptying rate, probably resulting in a slower release of AA (He and Giuseppin, 2014). Casein micelles have been reported to have different digestion behaviors from the individual caseins (Miranda and Pelissier, 1981). In an in vivo gastric digestion study, in a rat stomach, the coagulation of skim milk was much greater than that of a sodium caseinate solution. In addition, the gastric emptying rate and the hydrolysis rate of a mixture of individual caseins were much faster than those of skim milk (Miranda and Pelissier, 1981). This difference in digestion behavior between caseinates and casein micelles occurs primarily because casein micelles can be coagulated by the milk-clotting enzyme pepsin (Tam and Whitaker, 1972) and an acidic pH (Dalgleish and Corredig, 2012), whereas caseinate is coagulated only by low pH and not by an enzyme (Van Slyke and Bosworth, 1913).

In the present work, the physicochemical behavior and the curd formation of different commercial dairy protein ingredients during in vitro gastric digestion were investigated using a dynamic digestion model [i.e., a human gastric simulator (HGS)]. The dynamic model allows a more real environment in which to simulate the human gastric digestion process (Kong and Singh, 2010), mimicking gastric contraction, the continuous addition of fresh simulated gastric fluid (SGF) that contains pepsin, and simulated gastric emptying. The results offer novel insights about the coagulation kinetics of proteins from different milk protein ingredients, highlighting the critical role of the food matrix in affecting the course of protein digestion. The information obtained from this study will be useful in understanding the digestion of different commercial dairy ingredients and for the design and development of different products derived from these dairy ingredients.

\section{MATERIALS AND METHODS}

\section{Materials}

In this study, commercial dairy ingredients, including SMP, MPC (4851), MPC (4861), sodium caseinate (180), and WPI (895), were purchased from Fonterra Co-operative Group Ltd. (Auckland, New Zealand). The compositions of the dairy ingredients, as stated by the manufacturer, are given in Table 1 . The MPC (4851) contains 2,160 $\mathrm{mg}$ of calcium/100 $\mathrm{g}$, and the MPC (4861) contains 1,260 mg of calcium/100 g. The calcium-depleted MPC (4861) was manufactured using cation exchange to replace the divalent ions with monovalent ions and then ultrafiltration and diafiltration (Dybing et al., 2002). Pepsin from porcine gastric mucosa (EC 3.4.23.1; catalog no. 1.07185.0100) was purchased from Merck (Darmstadt, Germany); it had an activity of 0.7 FIP-U/mg, as stated by the manufacturer.

Water was purified by treatment with a Milli-Q apparatus (Millipore Corp., Bedford, MA) and was used for all experiments. All chemicals used were of analytical grade and were purchased from Sigma Chemical Co. (St. Louis, MO) or BDH Chemicals (BDH Ltd., Poole, UK) unless otherwise specified.

\section{Methods}

Preparation of Protein Solution. A 200-g 3.0\% (wt/wt) protein solution was prepared by dissolving the milk protein ingredient in Milli-Q water. It was stirred 
Table 1. The composition of dairy ingredients

\begin{tabular}{lrrrrr}
\hline & $\begin{array}{c}\text { Protein } \\
(\mathrm{g} / 100 \mathrm{~g})\end{array}$ & $\begin{array}{c}\text { Moisture } \\
(\mathrm{g} / 100 \mathrm{~g})\end{array}$ & $\begin{array}{c}\text { Fat } \\
(\mathrm{g} / 100 \mathrm{~g})\end{array}$ & $\begin{array}{c}\text { Total } \\
\text { carbohydrate } \\
(\mathrm{g} / 100 \mathrm{~g})\end{array}$ & $\begin{array}{c}\text { Ash } \\
(\mathrm{g} / 100 \mathrm{~g})\end{array}$ \\
\hline Skim milk powder & 33.4 & 3.8 & 0.8 & 54.1 & 7.9 \\
MPC (4851) & 82.9 & 5.6 & 1.4 & 3.3 & 6.8 \\
Calcium-depleted MPC (4861) & 81.8 & 5.8 & 1.4 & 4.0 & 7.0 \\
Sodium caseinate (SureProtein 180) & Min 95.0 & Max 5.5 & Max 1.5 & - & Max 4.0 \\
WPI (Instantised 895) & 93.0 & 4.8 & 1.0 & 0.3 & 1.7 \\
\hline
\end{tabular}

${ }^{1}$ These ingredients were purchased from Fonterra Co-operative Group Ltd. (Auckland, New Zealand). MPC $=$ milk protein concentrate; WPI $=$ whey protein isolate; Min $=$ minimum; Max $=$ maximum.

and placed in a water bath at constant temperature $\left(50^{\circ} \mathrm{C}\right)$ for $2 \mathrm{~h}$ to ensure complete dissolution.

$\boldsymbol{S G F}$. Simulated gastric fluid was prepared according to a method in a previous study (Minekus et al., 2014) with a slight modification. A solution of a fresh mixture of $\mathrm{KCl}(6.9 \mathrm{mmol} / \mathrm{L}), \mathrm{KH}_{2} \mathrm{PO}_{4}(0.9 \mathrm{mmol} / \mathrm{L}), \mathrm{NaHCO}_{3}$ $(25 \mathrm{mmol} / \mathrm{L}), \mathrm{NaCl}(47.2 \mathrm{mmol} / \mathrm{L}), \mathrm{MgCl}_{2}\left(\mathrm{H}_{2} \mathrm{O}\right)_{6}(0.1$ $\mathrm{mmol} / \mathrm{L})$, and $\left(\mathrm{NH}_{4}\right)_{2} \mathrm{CO}_{3}(0.5 \mathrm{mmol} / \mathrm{L})$ was prepared by dissolving these ingredients in deionized water with stirring for $30 \mathrm{~min}$. A total of $800 \mathrm{~mL}$ of water was then added to reach a final volume of SGF of $1 \mathrm{~L}$ (i.e., a $1.25 \times$ concentrate). The addition of pepsin $(4.8 \mathrm{~g} / \mathrm{L})$, $\mathrm{CaCl}_{2}(0.15 \mathrm{mmol} / \mathrm{L})$, and water would result in the correct electrolyte concentration. Pepsin and $\mathrm{CaCl}_{2}$ were added before use. The $\mathrm{pH}$ of the SGF was adjusted to 1.5 using $1 \mathrm{M} \mathrm{HCl} / \mathrm{NaOH}$.

HGS. A HGS, designed by Kong and Singh (2010), was employed for in vitro gastric digestion. A 200-g protein solution was fed into the HGS and was warmed at $37^{\circ} \mathrm{C}$ for $2 \mathrm{~min}$. The SGF was then added at a rate of $2.5 \mathrm{~mL} / \mathrm{min}$ (the addition rates of the $1.25 \times$ concentrated SGF and the pepsin were 2.0 and $0.5 \mathrm{~mL} / \mathrm{min}$, respectively, and were controlled by 2 separate pumps). Samples $(50 \mathrm{~mL})$ of digesta were removed from the bottom of the stomach chamber at 20-min intervals, equaling an emptied digesta rate of $2.5 \mathrm{~mL} / \mathrm{min}$. The gastric contraction frequency was 3 times/min, to mimic the actual contraction of the stomach. The temperature of the HGS was set and maintained at $37^{\circ} \mathrm{C}$ by a heater and a thermostat during the $220 \mathrm{~min}$ of gastric digestion. At each time interval, the sample was removed from the HGS and then filtered through a mesh with a pore size of $1 \mathrm{~mm}$ for further analysis, so that only the solid mass of size $\leq 1 \mathrm{~mm}$ was emptied. Measurement of the $\mathrm{pH}$ and weight of the curd and confocal microscopy observation were carried out immediately before the pepsin inactivation. Then the digesta and curd samples were heated at $90^{\circ} \mathrm{C}$ for $3 \mathrm{~min}$ to inactivate pepsin for further analysis by SDS-PAGE. In a control experiment, instead of the sample, $200 \mathrm{~g}$ of Milli-Q water was fed into the HGS and digested for $220 \mathrm{~min}$.
pH Measurement. The initial $\mathrm{pH}$ in the HGS was defined as the $\mathrm{pH}$ of the freshly prepared milk protein solution. With the ingestion of SGF $(2.5 \mathrm{~mL} / \mathrm{min})$ and gastric emptying $(2.5 \mathrm{~mL} / \mathrm{min})$, the $\mathrm{pH}$ in the HGS at different times was assumed to be that of the emptied digesta, because the setup (roller contraction) prevented easy access into the HGS.

Weight of Curd. After 220 min of digestion, the curd (if any) was collected and filtered through a sieve with a 1-mm pore size to separate the aqueous phase and the curd. The curd was then rinsed with SGF to remove pepsin from the surface and was weighed immediately. It was then heated at $90^{\circ} \mathrm{C}$ for $3 \mathrm{~min}$ to inactivate the pepsin and put in the vacuum oven at $105^{\circ} \mathrm{C}$ to determine its dry weight.

Confocal Laser Scanning Microscopy. The microstructure of the curd obtained from the digestion was studied using a confocal laser scanning microscope (Leica, Heidelberg, Germany). Fast Green (fluorescent dye) was used to stain for protein (He-Ne laser with an excitation line at $633 \mathrm{~nm}$ ). The images were recorded to observe the change in the microstructure of the samples during digestion. A small piece of curd was stained with 1.0\% (wt/vol) Fast Green for 15 min, placed on a concave confocal microscope slide (Sail; Sailing MedicalLab Industries Co. Ltd., Suzhou, China), covered with a coverslip, and examined with a $63 \times$ magnification lens.

Protein Hydrolysis. The time-dependent hydrolysis by pepsin of the proteins in the curd and the emptied digesta was determined by analyzing the protein composition of the samples as a function of the digestion time, using SDS-PAGE. Liquid digesta samples were mixed with sample buffer at a ratio of $1: 2(\mu \mathrm{L})$, and $8 \mu \mathrm{L}$ of the mixture was loaded in each well. For solid curd samples, $4.5 \mathrm{mg}$ of the freeze-dried and ground powder was mixed with $1 \mathrm{~mL}$ of sample buffer, and 10 $\mu \mathrm{L}$ of this was loaded in each well.

Statistical Analysis. Each experiment was performed at least twice using freshly prepared samples. The results are reported as the calculated means and 


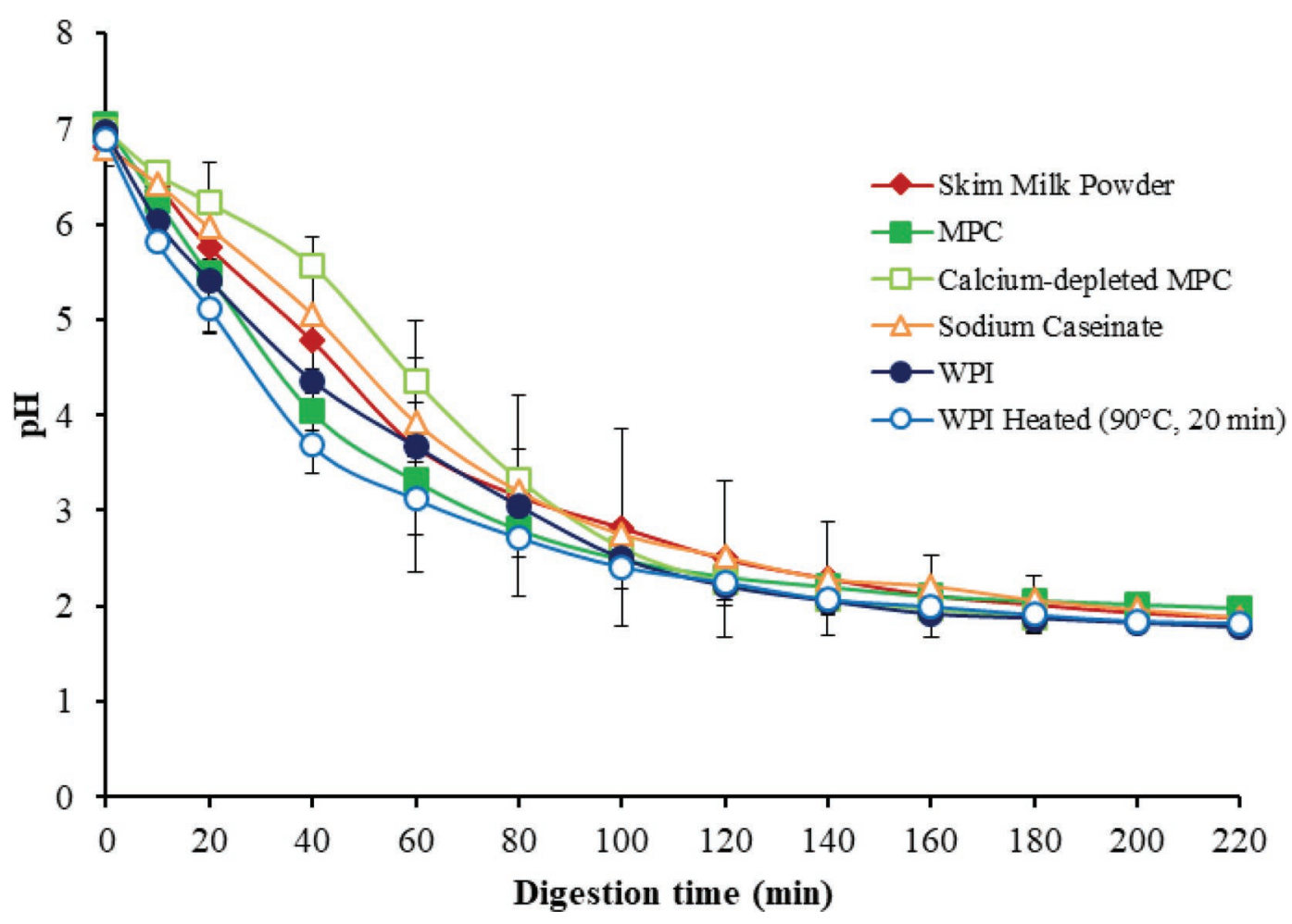

Figure 1. Changes in $\mathrm{pH}$ (mean $\pm \mathrm{SD}$ ) during gastric digestion of different dairy ingredient solutions containing $3.0 \%$ (wt/wt) protein in the human gastric simulator. MPC $=$ milk protein concentrate; WPI $=$ whey protein isolate. Color version available online.

standard deviations. One-way ANOVA and the SPSS 19.0 package (IBM, Armonk, NY) were used. Duncan's multiple range tests were used to determine the significant difference of the mean values $(P<0.05)$.

\section{RESULTS}

\section{pH Profiles}

Figure 1 shows the changes in the $\mathrm{pH}$ of the emptied digesta from various dairy ingredients as a function of the digestion time. In general, with the gradual addition of $\mathrm{SGF}$ at a rate of $2.5 \mathrm{~mL} / \mathrm{min}$, the $\mathrm{pH}$ of all ingredients (i.e., the $\mathrm{pH}$ of the emptied digesta) decreased with an increase in the digestion time. The initial $\mathrm{pH}$ in the stomach represented the $\mathrm{pH}$ of the different dairy ingredient solutions containing $3.0 \%$ (wt/wt) protein and ranged from $\mathrm{pH} 6.79 \pm 0.18$ to $\mathrm{pH} 7.05 \pm 0.03$ (mean $\pm \mathrm{SD}$ ). The $\mathrm{pH}$ profiles of the dairy ingredients used were different during the early digestion period. Calcium-depleted MPC had a slower decrease in $\mathrm{pH}$ with increasing digestion time than the other dairy ingredients, reaching $\mathrm{pH} \sim 5.6$ within 40 min and $\mathrm{pH} \sim 2.0$ after $140 \mathrm{~min}$. In contrast, heated WPI had the fastest decrease in $\mathrm{pH}$, decreasing to $\mathrm{pH} \sim 3.4$ within the first 40 min and to close to $\mathrm{pH} \sim 2.0$ at 120 min. Skim milk powder, MPC, sodium caseinate, and WPI had only slight differences their $\mathrm{pH}$ profiles. The decrease in $\mathrm{pH}$ was slower in SMP and sodium caseinate than in MPC and WPI. However, with further digestion, the $\mathrm{pH}$ of all ingredients did not change significantly from 120 to $220 \mathrm{~min}$.

\section{Coagulation Behavior of Milk Protein Ingredients}

Figure 2 shows the curds obtained from $200 \mathrm{~g}$ of the dairy ingredient solutions after $220 \mathrm{~min}$ of gastric digestion. In general, the appearances of the curds from all ingredients were different. For SMP and MPC, protein coagulation was visible in the first 10 min of digestion, and the serum phase gradually became clear during this period. The $\mathrm{pH}$ values at $10 \mathrm{~min}$ of digestion were 6.40 and 6.22 for SMP and MPC, respectively. Over the 220 min of digestion, a cheese-like curd with a closely knit network and a ball-like shape was observed in SMP and MPC. However, these 2 curds were slightly different in appearance. The curd from SMP contained numerous loose, crumbled fragments, many more than were observed in MPC. The curd obtained from MPC was a more integrated ball-like pellet (Figure 2).

For calcium-depleted MPC, protein coagulation was visible after $40 \mathrm{~min}$ of digestion. Sodium casein- 
ate produced a large amount of white precipitate after $40 \mathrm{~min}$, and the serum phase became clear again after almost $60 \mathrm{~min}$ of digestion. However, over the $220 \mathrm{~min}$ of digestion, a loose, fragmented protein matrix with several large voids was consistently observed in the curds formed from calcium-depleted MPC and sodium caseinate (Figure 2). No curd was observed in unheated or heated WPI after 220 min of digestion. However, aggregation occurred in heated WPI after $40 \mathrm{~min}$ of digestion, but no aggregation was observed after 120 min. In contrast, no aggregation occurred in native WPI during the whole digestion period.

The microstructures of the curds, observed by confocal microscopy, are shown in Figure 3. Much denser and smaller pores within the protein network were observed in the curd obtained from SMP (Figure 3A). For MPC, almost no pores can be observed in the smooth blocks of protein; the porosity of the network structure was no longer observed within the large protein mass (Figure 3B). In contrast, many large and uneven pores separated from the protein network were observed in the curd of calcium-depleted MPC (Figure 3C).

The dried weights of the curds obtained from the different dairy ingredients after $220 \mathrm{~min}$ of digestion, using a vacuum oven to dry the curds at $105^{\circ} \mathrm{C}$ overnight, were significantly different $(P<0.01$; Figure 4$)$. The dried weights of the SMP and MPC curds were about
3.24 and $2.85 \mathrm{~g}$, respectively. Both were significantly greater $(P<0.05)$ than those of the curds of calciumdepleted MPC and sodium caseinate.

\section{Protein Hydrolysis in the Curds}

Sodium dodecyl sulfate-PAGE under reducing conditions was used to determine the protein composition and the hydrolysis of the curds obtained after $220 \mathrm{~min}$ of gastric digestion in the HGS (Figure 5). For all ingredients, the $\kappa-\mathrm{CN}$ band was faint and a new band appeared at around $15 \mathrm{kDa}$; it was probably para- $\kappa$ CN (Miranda and Pelissier, 1983). $\alpha_{\mathrm{S}^{-}}$Casein $\left(\alpha_{\mathrm{S}^{-}} \mathrm{CN}\right.$ $\left.+\alpha_{\mathrm{S}_{2}} \mathrm{CN}\right)$ and $\beta$-LG bands were clearly observed for SMP and MPC but were much less apparent for calcium-depleted MPC and sodium caseinate. Furthermore, multiple peptide bands with different molecular weights (ranging from 10 to $20 \mathrm{kDa}$ ) were clear for all ingredients. However, the relative band intensities of the peptides were much greater for calcium-depleted MPC and sodium caseinate than for SMP and MPC.

\section{SDS-PAGE Patterns of the Emptied Digesta}

Sodium dodecyl sulfate-PAGE patterns of the emptied digesta from the different dairy ingredients as a

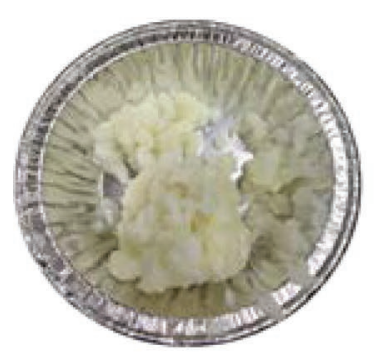

Skim Milk Powder

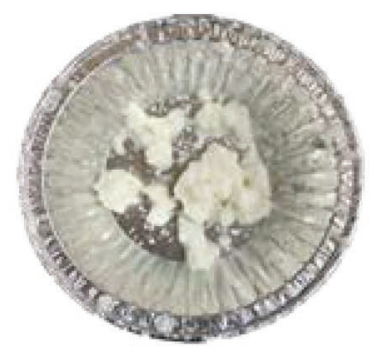

Sodium Caseinate

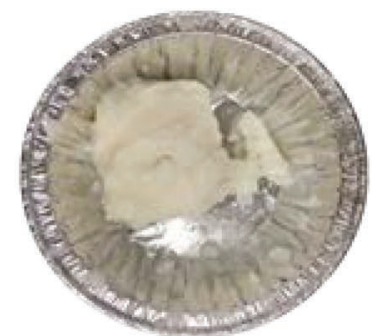

MPC

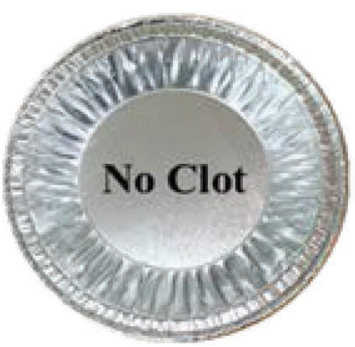

WPI

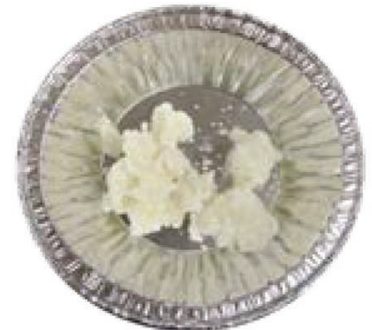

Calcium-depleted MPC

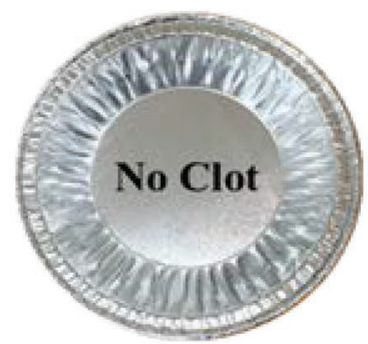

Heated WPI $\left(90^{\circ} \mathrm{C}, 20 \mathrm{~min}\right)$

Figure 2. Images of curds obtained from $200 \mathrm{~g}$ of dairy ingredient solutions containing $3.0 \%$ (wt/wt) protein after $220 \mathrm{~min}$ of digestion in the human gastric simulator. MPC = milk protein concentrate; WPI = whey protein isolate. Color version available online. 


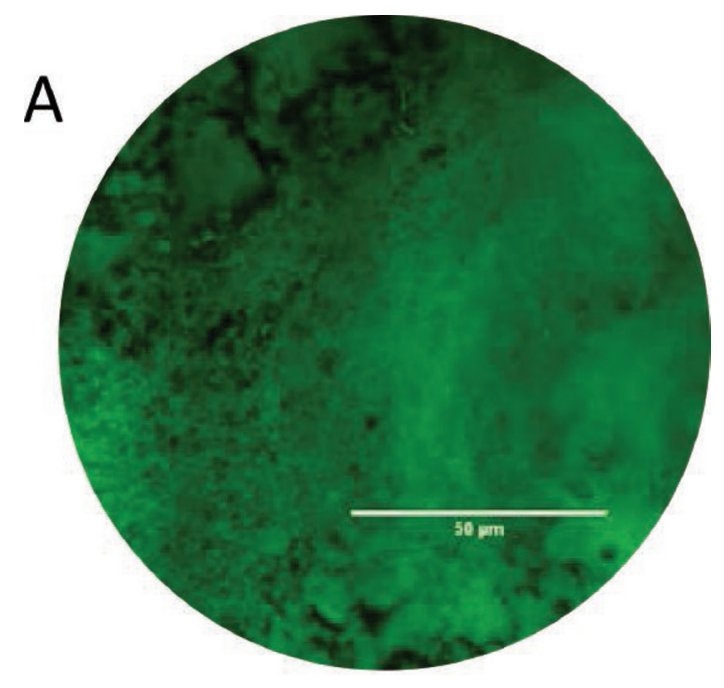

function of digestion time are shown in Figure 6. After 5 min of digestion, the digesta from SMP, MPC, calciumdepleted MPC, and sodium caseinate contained intact $\alpha_{S}-\mathrm{CN}$ and $\beta-\mathrm{CN}$. For these ingredients, the intensity of the $\mathrm{k}-\mathrm{CN}$ band was much less than that observed before digestion, and a newly formed band appeared clearly at around $\sim 15 \mathrm{kDa}$, probably consisting of para$\kappa-\mathrm{CN}$. With increasing digestion time, the intensity of the para-k-CN band decreased very rapidly and was not observed in the digesta from these 4 ingredients after $80 \mathrm{~min}$ of digestion.

For SMP and MPC, after $20 \mathrm{~min}$ of digestion, the $\alpha_{S^{-}}-\mathrm{CN}$ and $\beta-\mathrm{CN}$ bands had become very faint, whereas the $\kappa-\mathrm{CN}$ and para- $\kappa-\mathrm{CN}$ bands could still be observed for MPC but had disappeared for SMP (Figures 6A and $6 \mathrm{~B}$ ). All casein bands in the emptied digesta had disappeared after $40 \mathrm{~min}$ of digestion for both SMP and MPC. Intact $\beta-\mathrm{LG}, \alpha-\mathrm{LA}$, and BSA were present in the emptied digesta for SMP and MPC at 5 min of digestion. With further digestion, the band intensities of $\alpha-\mathrm{LA}$ and BSA decreased rapidly, with the $\alpha$-LA band disappearing after $80 \mathrm{~min}$ for SMP and MPC. However, the BSA band was not observed after 20 and 40 min of digestion for SMP and MPC, respectively. $\beta$-Lactoglobulin was observed in the emptied digesta for MPC until $160 \mathrm{~min}$ of digestion, whereas it was absent at 80 min for SMP.

The SDS-PAGE of the emptied digesta from calciumdepleted MPC (Figure 6C) showed a similar pattern to that of the emptied digesta from sodium caseinate (Figure 6D). The intensities of the casein bands decreased gradually with an increase in digestion time, becoming very faint at $40 \mathrm{~min}$ and disappearing at $80 \mathrm{~min}$ for calcium-depleted MPC and sodium caseinate. Furthermore, numerous peptide bands with molecular weights ranging from $\sim 10$ to $15 \mathrm{kDa}$ were observed at $40 \mathrm{~min}$ of digestion for both ingredients. For calcium-depleted MPC, BSA and $\alpha$-LA bands were not observed at 40 and $80 \mathrm{~min}$, respectively; the $\beta-\mathrm{LG}$ band was retained for longer, disappearing at $160 \mathrm{~min}$ of digestion.

Figures $6 \mathrm{E}$ and $6 \mathrm{~F}$ present the SDS-PAGE patterns of the emptied digesta obtained from unheated WPI and heated WPI, respectively. After 5 min of digestion, intact $\beta-\mathrm{LG}, \alpha-\mathrm{LA}$, and BSA were clearly visible in the digesta for native and heated WPI. For unheated WPI, $\beta$-LG remained intact during the whole digestion period and appeared to decrease gradually in intensity with an increase in the digestion time. In contrast, from 5 to $40 \mathrm{~min}$, the intensity of the $\beta$-LG band for heated WPI was much less than that for unheated WPI; it

Figure 3. Confocal micrographs of curds from $200 \mathrm{~g}$ of dairy ingredient solutions containing 3.0\% (wt/wt) protein after $220 \mathrm{~min}$ of digestion in the human gastric simulator. (A) Skim milk powder, (B) milk protein concentrate, and (C) calcium-depleted milk protein concentrate. Scale bar $=50 \mu \mathrm{m}$. Color version available online. had almost disappeared at 80 min of digestion. For unheated and heated WPI, clear and intact $\alpha$-LA bands were present during the first $40 \mathrm{~min}$ of digestion but had disappeared at $80 \mathrm{~min}$. Bovine serum albumin re- 


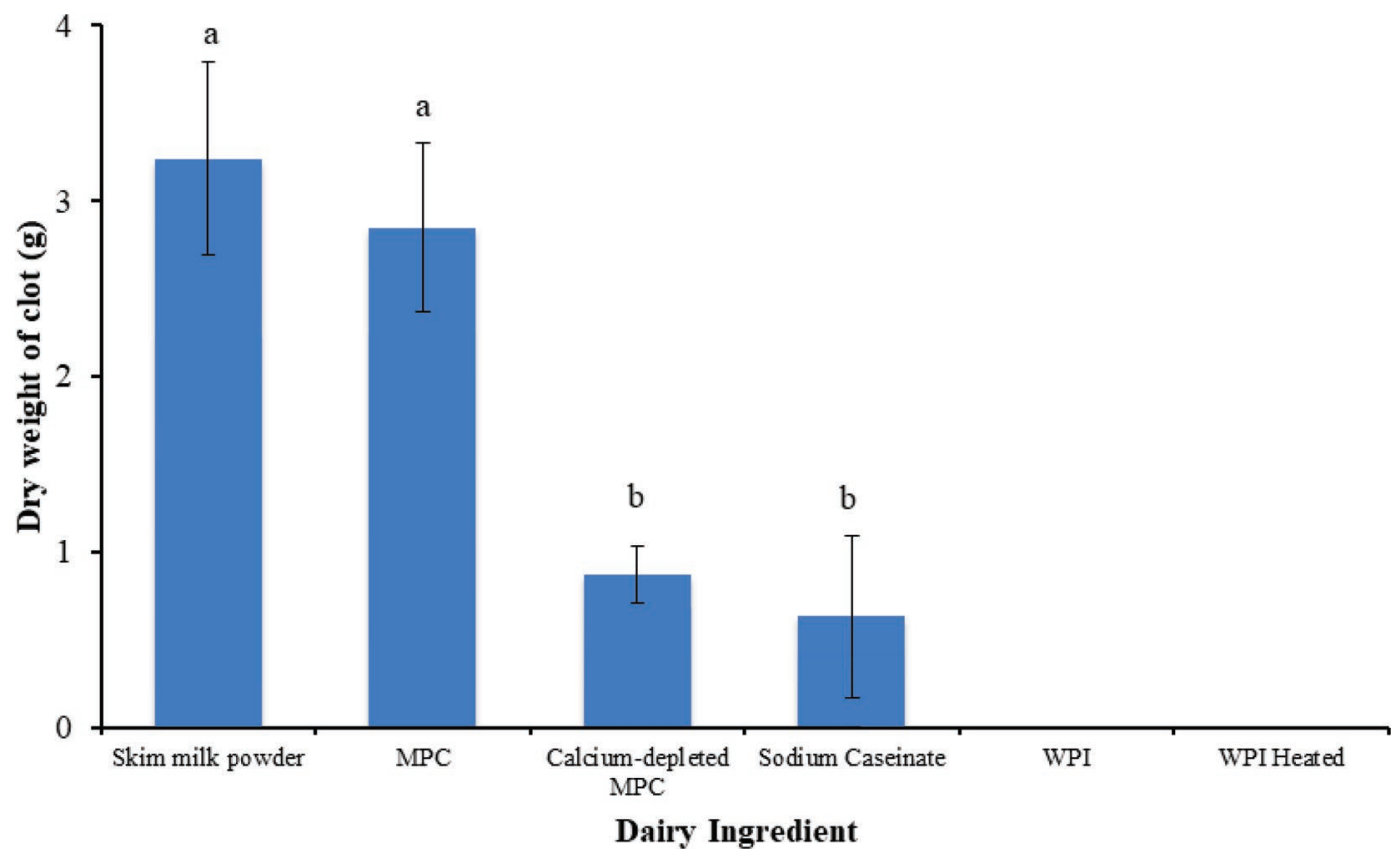

Figure 4. Dry weight of curds (mean $\pm \mathrm{SD}$ ) obtained from $200 \mathrm{~g}$ of dairy ingredient solutions containing $3.0 \%$ (wt/wt) protein after $220 \mathrm{~min}$ of digestion in the human gastric simulator. Different letters $(\mathrm{a}, \mathrm{b})$ indicate significant differences $(P<0.05)$ among the dairy ingredients. MPC $=$ milk protein concentrate; $\mathrm{WPI}=$ whey protein isolate. Color version available online.

mained intact during the first 20 min of digestion for unheated and heated WPI but had disappeared from the emptied digesta at 80 and 40 min of digestion for unheated and heated WPI, respectively. Furthermore, a large amount of peptides was clearly visible in the emptied digesta from heated WPI at 40 min of digestion, whereas no peptides were observed in the digesta from unheated WPI during the whole digestion period.

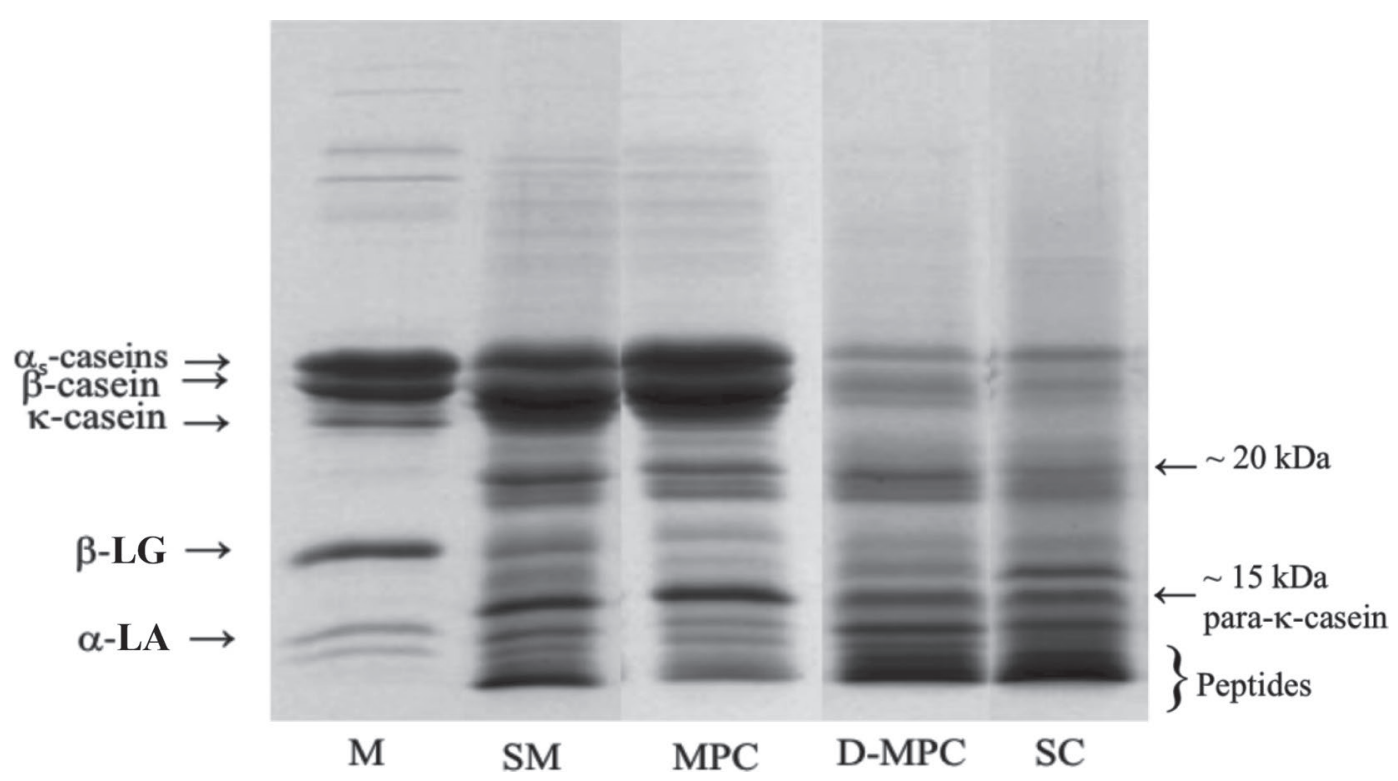

Figure 5. Sodium dodecyl sulfate-PAGE patterns of curds collected from different dairy ingredient solutions after $220 \mathrm{~min}$ of digestion in the human gastric simulator. $\mathrm{M}=$ trim milk; $\mathrm{SM}=$ skim milk powder; $\mathrm{MPC}=$ milk protein concentrate; $\mathrm{D}-\mathrm{MPC}=$ calcium-depleted milk protein concentrate; $\mathrm{SC}=$ sodium caseinate. 


\section{DISCUSSION}

In general, for all dairy protein ingredients, $\mathrm{pH}$ decreased with an increase in the digestion time; however, the rate of decrease was different for the different ingredients used (Figure 1). This difference can be attributed to the formation of curds with various structures in the different dairy ingredients. Therefore, the diffusions of ions and molecules into and out of the coagulum were different (Ye et al., 2016b). This difference is probably also related to the different buffering capacities of the milk proteins contained in the ingredients, especially between casein-based ingredients (MPC and caseinate) and whey protein-based ingredients (WPI and heated WPI). The $\mathrm{pH}$ decreased rapidly with increasing digestion time for WPI and heated WPI because whey protein has a lower buffering capacity than casein-based ingredients (MPC and caseinate; Walstra and Jenness, 1984). However, the sharp reduction in the $\mathrm{pH}$ of MPC may have been because it formed a curd at an earlier digestion time.

Skim milk powder and MPC showed similar digestion behaviors during the 220 min of gastric digestion. In general, considerable protein coagulation was visible within the first $10 \mathrm{~min}$ of digestion. The emptied digesta contained very little protein after 20 min of diges-
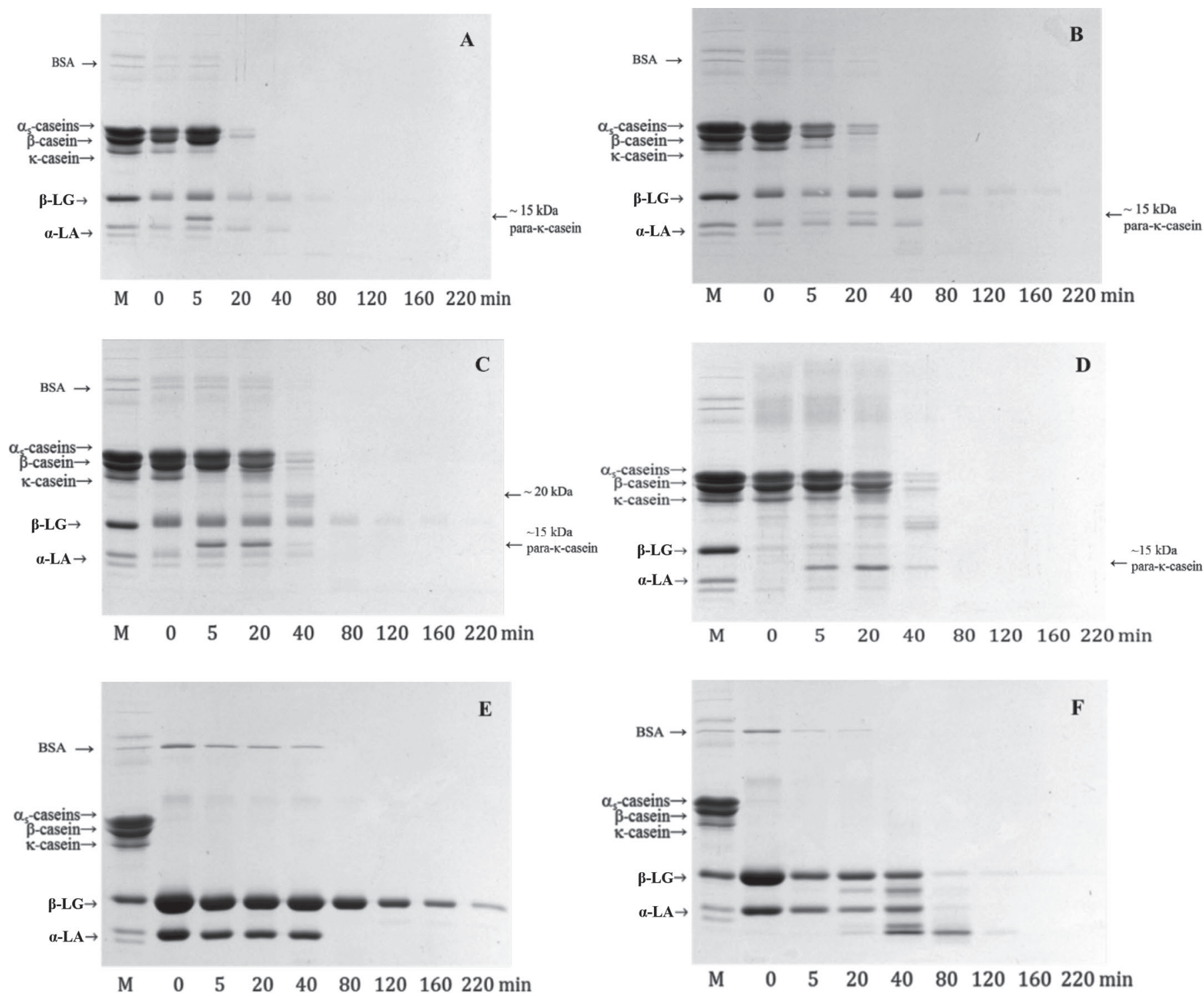

Figure 6. Sodium dodecyl sulfate-PAGE patterns of emptied digesta collected from different dairy ingredient solutions during 220 min of digestion in the human gastric simulator. $\mathrm{M}=$ trim milk. (A) Skim milk powder; (B) milk protein concentrate; (C) calcium-depleted milk protein concentrate; (D) sodium caseinate; $(\mathrm{E})$ whey protein isolate; $(\mathrm{F})$ heated $\left(90^{\circ} \mathrm{C}, 20 \mathrm{~min}\right)$ whey protein isolate. 
tion. The curd remained in the stomach as a ball-like shape with a closely knit network over the $220 \mathrm{~min}$ of digestion. Protein coagulation started at $\mathrm{pH}$ values of $\sim 6.40$ and 6.22 for SMP and MPC, respectively, which are far above the $\mathrm{pH}$ region of acid coagulation (isoelectric point of caseins $=4.6$ ). Furthermore, as observed from the SDS-PAGE, newly formed bands occurred at about $\sim 15 \mathrm{kDa}$, and the $\mathrm{k}-\mathrm{CN}$ bands were faint in the emptied digesta from SMP and MPC after $5 \mathrm{~min}$ of digestion (Figures $6 \mathrm{~A}$ and $6 \mathrm{~B}$ ). These bands at $15 \mathrm{kDa}$ were probably the degradation product of $\kappa$-casein, para-k-CN (Miranda and Pelissier, 1983). The initial hydrolysis rate of $\kappa-\mathrm{CN}$ by pepsin is known to be faster than that of other caseins at $\mathrm{pH} 6.0$ during in vitro digestion (Tam and Whitaker, 1972). These observations indicate that the initial protein coagulation behavior was driven by the action of the milk-clotting enzyme pepsin on the micellar $\kappa-\mathrm{CN}$, causing destabilization of the casein micelles (Tam and Whitaker, 1972). These changes in the milk proteins in the early stages of digestion are consistent with the digestion of skim milk and whole milk, with different treatments reported in previous studies in our laboratory (Ye et al., 2016a,b, 2017).

For SMP and MPC, over the 220 min of digestion, the curds did not break down into small pieces or disappear. After $220 \mathrm{~min}$, the wet weight and the dry weight of the curds obtained from SMP and MPC were significantly greater $(P<0.05)$ than those obtained from sodium caseinate and calcium-depleted MPC (Figure 4). The curds obtained from SMP and MPC remained intact during the whole digestion period, which can be attributed to their characteristic structure. Previous work in our laboratory demonstrated that the curd formed from skim milk under gastric conditions was degraded only on its surface, because of its relatively limited surface area, leading to a relatively slow proteolysis of caseins by pepsin during in vitro digestion (Ye et al., 2016b). Such a dense pellet-like structure allows only a limited amount of pepsin from SGF to diffuse and permeate to the inside of the curd and hydrolyze the caseins. This was confirmed by the electrophoretic analysis results for the curds (Figure 5), which showed that caseins were still present in the curds in considerable amounts after 220 min of digestion.

However, the structures of the curds derived from SMP and MPC were slightly different. The SMP curd contained a much larger number of fragmented, aggregated protein blocks than the MPC curd (Figure 3). This difference can be attributed primarily to the different processing technologies applied to these ingredients. All ingredients used in the present study were commercial dairy protein ingredients, that is, they had been processed by thermal treatment under specific temperature conditions or by a membrane technique. The SMP used in the present study has a whey protein nitrogen index of between 1.51 and $5.99 \mathrm{mg} / \mathrm{g}$, which indicates that the whey proteins had been partly denatured by preheating during the manufacturing process. Thus, denatured $\beta-\mathrm{LG}$ was involved in the formation of the SMP curd, which was detected by SDS-PAGE (Figure 5), because a conformational unfolding is induced by preheating and causes the association of $\beta$-LG with casein micelles via micellar $\kappa$-CN (Anema and $\mathrm{Li}, 2003)$. These small, fragmented protein blocks remained separated in the loose and crumbled structure during the whole digestion period; this is similar to the curd formed in the renneting of heated milk that is less cohesive (Anema et al., 2007).

Milk protein concentrate is manufactured using a combined ultrafiltration and diafiltration process. During these processes, colloidal calcium phosphate may be partly dissolved, resulting in loose casein micelle structures and partial dissociation of caseins from the micelles (Singh, 2007). However, it is likely that MPC still contains a relatively intact casein micelle structure. It may be coagulated by pepsin and may form an integrated curd under gastric conditions, as observed in skim milk (Ye et al., 2016b). Compared with MPC, most of the casein micelles are dissociated when the calcium is removed in calcium-depleted MPC (Ye, 2011). Therefore, the digestion behavior of calcium-depleted MPC appears to be significantly different from that of MPC but somewhat similar to that of sodium caseinate. For calcium-depleted MPC and sodium caseinate, precipitation and coagulation of the caseins occurred mainly at longer digestion times (about 40 min of digestion). This observation was further confirmed by SDS-PAGE of the emptied digesta (Figures $6 \mathrm{C}$ and $6 \mathrm{D}$ ). At this digestion time, the $\mathrm{pH}$ values $(\mathrm{pH}<5)$ in the stomach were close to the isoelectric point of caseins. The difference in digestion behavior between calcium-depleted MPC, sodium caseinate, and MPC may be attributed a lack of intact casein micelles and the presence of only individual caseins in calcium-depleted MPC and sodium caseinate. The coagulation behavior of casein molecules is different from that of casein micelles. That is, casein is coagulated only by acidic $\mathrm{pH}$ and not by pepsin (Dalgleish and Corredig, 2012). Therefore, coagulation occurred in calcium-depleted MPC and sodium caseinate at longer digestion times, as the $\mathrm{pH}$ gradually decreased to $\mathrm{pH}<5.0$ with the addition of SGF.

Furthermore, over the 220 min of digestion, the curds observed in calcium-depleted MPC and sodium caseinate were a few separated, aggregated protein blocks with small size and a loose, open network (Figure 3). Such a structure was more accessible to pepsin hydro- 
lysis, resulting in a large amount of hydrolysis product in the curds derived from both calcium-depleted MPC and sodium caseinate (Figure 5).

For unheated WPI, $\beta$-LG remained intact without being degraded during the whole digestion period (Figure $6 \mathrm{E}$ ), because native $\beta-\mathrm{LG}$ is resistant to hydrolysis by pepsin because of its compact globular structure (Reddy et al., 1988; Sarkar et al., 2009). The decrease with time probably occurred because of dilution of the stomach contents by gastric juices. However, for heated WPI, a lesser amount of $\beta$-LG was observed in the emptied digesta and almost all was degraded from the digesta at $80 \mathrm{~min}$, which can be attributed to the hydrolysis by pepsin. Because the conformation of the protein may unfold after heating a $\beta$-LG solution above its denaturation temperature for 10 to $15 \mathrm{~min}$, some potential cleavage sites for pepsin (i.e., buried hydrophobic AA residues) may be exposed. This makes $\beta$-LG more susceptible to pepsin hydrolysis (Guo et al., 1995; Anema and Li, 2003). Therefore, for heated WPI, a considerable amount of enzymatic degradation products (i.e., peptides) was detected by electrophoretic analysis in the emptied digesta after $20 \mathrm{~min}$ of digestion (Figure $6 \mathrm{~F}$ ).

The digestion behavior of $\alpha$-LA did not show any significant difference between unheated and heated WPI. The disappearance or a faintness of the $\alpha$-LA band was observed at about $80 \mathrm{~min}$ of digestion in the emptied digesta for unheated and heated WPI. At this time point, the $\mathrm{pH}$ of the digesta for unheated and heated WPI were about 3.05 and 2.51, respectively. This probably occurred because when the $\mathrm{pH}$ of digestion is lower than 4.0, $\alpha$-LA and $\beta$-LG are more accessible to hydrolysis by pepsin (Miranda et al., 1989).

\section{CONCLUSIONS}

During dynamic gastric digestion, SMP and MPC, which contained casein micelles, started to form a coagulum in the early digestion period (in the first 10 min) and at high $\mathrm{pH}(\mathrm{pH}>6)$. However, partly calciumdepleted MPC and sodium caseinate, which contained no intact casein micellar structure, formed a coagulum at $\mathrm{pH}<5$ after $40 \mathrm{~min}$ of digestion. The curds observed in SMP and MPC had a closely knit structure, resembling a firm cheese ball, and had a much greater weight than the curds observed in calcium-depleted MPC and sodium caseinate. After 220 min of digestion, the curds for partly calcium-depleted MPC and sodium caseinate consisted of numerous small, loose, fragmented protein blocks. Such different structures apparently influenced the rate of protein hydrolysis by pepsin of the different dairy protein ingredients under gastric conditions. The hydrolysis of the curds derived from SMP and MPC was much slower than that of those derived from partly calcium-depleted MPC and sodium caseinate. Native WPI remained soluble in the stomach and passed through the stomach; the emptied digesta indicated that $\beta$-LG was not hydrolyzed by pepsin during the whole period of gastric digestion. In contrast, heated WPI was rapidly hydrolyzed by pepsin and formed aggregates when the $\mathrm{pH}$ was close to the isoelectric point of the whey proteins in the stomach. However, the aggregates were further hydrolyzed by pepsin with further digestion. The results suggest that curd formation occurs at different initial times and $\mathrm{pH}$ in different milk protein ingredients and that the structure of the curd is dependent on the protein composition, the integrity of the casein micelle, and the processing technology (preheating or membrane technique). These differences lead to different rates of protein hydrolysis of different milk protein ingredients in the stomach, resulting in different compositions of the digesta delivered to the next digestion step.

\section{ACKNOWLEDGMENTS}

The research was supported by the Tertiary Education Commission-Centre of Research Excellence (CoRE; Wellington, New Zealand) and a Massey University doctoral research dissemination grant (Palmerston North, New Zealand).

\section{REFERENCES}

Anema, S. G., S. K. Lee, and H. Klostermeyer. 2007. Effect of pH at heat treatment on the hydrolysis of $\kappa$-casein and the gelation of skim milk by chymosin. Lebensm. Wiss. Technol. 40:99-106.

Anema, S. G., and Y. Li. 2003. Association of denatured whey proteins with casein micelles in heated reconstituted skim milk and its effect on casein micelle size. J. Dairy Res. 70:73-83.

Bansal, N., and B. Bhandari. 2016. Functional milk proteins: Production and utilization-Whey-based ingredients. Pages 67-98 in Advanced Dairy Chemistry. Vol. 1B. Proteins: Applied Aspects. 4th ed. P. L. H. McSweeney and J. A. O'Mahony, ed. Springer, New York, NY.

Boirie, Y., M. Dangin, P. Gachon, M. P. Vasson, J. L. Maubois, and B. Beaufrère. 1997. Slow and fast dietary proteins differently modulate postprandial protein accretion. Proc. Natl. Acad. Sci. USA 94:14930-14935

Carr, A., and M. Golding. 2016. Functional milk proteins production and utilization: Casein-based ingredients. Pages 35-66 in Advanced Dairy Chemistry. Vol. 1B. Proteins: Applied Aspects. 4th ed. P. L. H. McSweeney and J. A. O'Mahony, ed. Springer, New York, NY.

Dalgleish, D. G., and M. Corredig. 2012. The structure of the casein micelle of milk and its changes during processing. Annu. Rev. Food Sci. Technol. 3:449-467.

Dybing, S. T., G. V. Bhaskar, F. P. Dunlop, A. M. Fayerman, and M. J. Whitton, inventors. 2002. Modified milk protein concentrates and their use in making gels and dairy products. New Zealand Dairy Board, assignee. Patent WO02082917.

Ferreira, A., C. Oliveira, and F. Rocha. 2003. The different phases in the precipitation of dicalcium phosphate dihydrate. J. Cryst. Growth 252:599-611. 
Guo, M. R., P. F. Fox, A. Flynn, and P. S. Kindstedt. 1995. Susceptibility of $\beta$-lactoglobulin and sodium caseinate to proteolysis by pepsin and trypsin. J. Dairy Sci. 78:2336-2344.

He, T., and M. L. Giuseppin. 2014. Slow and fast dietary proteins differentially modulate postprandial metabolism. Int. J. Food Sci. Nutr. 65:386-390.

Kong, F., and R. P. Singh. 2010. A human gastric simulator (HGS) to study food digestion in human stomach. J. Food Sci. 75:E627E635.

Minekus, M., M. Alminger, P. Alvito, S. Ballance, T. Bohn, C. Bourlieu, and D. Dupont. 2014. A standardised static in vitro digestion method suitable for food-An international consensus. Food Funct. 5:1113-1124.

Miranda, G., G. Hazé, P. Scanff, and J.-P. Pelissier. 1989. Hydrolysis of $\alpha$-lactalbumin by chymosin and pepsin. Effect of conformation and $\mathrm{pH}$. Lait 69:451-459.

Miranda, G., and J. P. Pelissier. 1981. In vivo studies on the digestion of bovine caseins in the rat stomach. J. Dairy Res. 48:319-326.

Miranda, G., and J. P. Pelissier. 1983. Kinetic studies of in vivo digestion of bovine unheated skim-milk proteins in the rat stomach. J. Dairy Res. 50:27-36.

Mulvihill, D. M., and M. P. Ennis. 2003. Functional milk proteins: Production and utilization. Pages 1-48 in Advanced Dairy Chemistry. Vol. 1. Proteins. 3rd ed. P. F. Fox and P. L. H. McSweeney, ed. Kluwer Acad., New York, NY.

Reddy, I. M., N. K. Kella, and J. E. Kinsella. 1988. Structural and conformational basis of the resistance of $\beta$-lactoglobulin to peptic and chymotryptic digestion. J. Agric. Food Chem. 36:737-741.
Sarkar, A., K. K. Goh, R. P. Singh, and H. Singh. 2009. Behaviour of an oil-in-water emulsion stabilised by $\beta$-lactoglobulin in an in vitro gastric model. Food Hydrocoll. 23:1563-1569.

Singh, H. 2007. Interactions of milk proteins during the manufacture of milk powders. Lait 87:413-423.

Singh, H., and L. K. Creamer. 1991. Denaturation, aggregation and heat stability of milk protein during the manufacture of SMP. J. Dairy Res. 58:269-283.

Tam, J. J., and J. R. Whitaker. 1972. Rates and extents of hydrolysis of several caseins by pepsin, rennin, Endothia parasitica protease and Mucor pusillus protease. J. Dairy Sci. 55:1523-1531.

Van Slyke, L. L., and A. W. Bosworth. 1913. Valency of molecules and molecular weights of casein and paracasein. J. Biol. Chem. $14: 227-230$

Walstra, P., and R. Jenness. 1984. Dairy Chemistry and Physics. Wiley, New York, NY.

Ye, A. 2011. Functional properties of milk protein concentrates: Emulsifying properties, adsorption and stability of emulsions. Int. Dairy J. 21:14-20.

Ye, A., J. Cui, D. Dalgleish, and H. Singh. 2016a. The formation and breakdown of structured clots from whole milk during gastric digestion. Food Funct. 7:4259-4266.

Ye, A., J. Cui, D. Dalgleish, and H. Singh. 2016b. Formation of a structured clot during the gastric digestion of milk: Impact on the rate of protein hydrolysis. Food Hydrocoll. 52:478-486.

Ye, A., J. Cui, D. Dalgleish, and H. Singh. 2017. Effect of homogenization and heat treatment on the behavior of protein and fat globules during gastric digestion of milk. J. Dairy Sci. 100:36-47. 